C. M. Segeren - G. C. M. M. de Jong-Gerrits

M. B. van 't Veer, on behalf of the Dutch Slide

Review Committee of Leukemias in Adults

\title{
AML-MO: clinical entity or waste basket for immature blastic leukemias? A description of 14 patients
}

\begin{abstract}
In the period from August 1991 to August 1994, the Dutch Slide Review Committee of Adult Leukemias classified 14 leukemias as AML-M0. We reviewed the clinical characteristics and response to therapy of these patients. Eight patients were male. Patients' age ranged from 7 to 77 years (medium age 62 years). There was a striking homogeneity in morphological appearance of the blasts, being small to medium-sized round cells with often an eccentric nucleus with fine chromatin, several distinct nucleoli, and a high nucleo-cytoplasmic ratio. In addition to myeloid-associated markers such as CD13 and CD33, the blasts of all patients were positive for CD34 and HLA-DR, pointing to their immature differentiation stage. TdT was present in the blasts of $71 \%, \mathrm{CD} 7$ was positive in the blasts of $42 \%$ of the patients. No consistent cytogenetic abnormalities were found. With respect to the treatment outcome, four patients achieved a complete remission after remission-induction treatment. The median survival was 4.5 months. Our present study shows AML-M0 to be an immature leukemia, uniform in morphology and immunological phenotype, with no consistent cytogenetic phenotype and with a poor clinical outcome.
\end{abstract}

Key words Minimally differentiated acute myeloid leukaemia (AML-MO) · Clinical characteristics · Morphology $\cdot$ Immunophenotype $\cdot$ Prognosis

\section{Introduction}

The classification of acute leukemias is based mainly on light-microscopic morphological and cytochemical characteristics. According to the FAB classification, if

\footnotetext{
C. M. Segeren (区) · G. C. M. M. de Jong-Gerrits

M. B. van 't Veer

Dr. Daniel den Hoed Cancer Center,

Department of Hematology, P. O. Box 5201,

3008 AE Rotterdam, The Netherlands
}

there is myeloperoxidase (MPO) in more than $3 \%$ of the blasts, the leukemia is of myeloid origin $[2,8]$. In the great majority of MPO-negative leukemias the lymphatic origin can be confirmed by immunological marker analysis. Some of the MPO-negative leukemias, however, are negative for lymphatic markers. These include: acute megakaryoblastic leukemias, described in the FAB classification as M7 [3], and immature leukemias, which may include immature monocytic, erythroid, or myeloid leukemias [1].

Recently, the FAB group designated leukemias with minimal myeloid differentiation as AML-M0 [4]. The diagnosis AML-M0 is made if less than $3 \%$ of the blasts are positive for MPO or the Sudan black B (SBB) reaction and if the blasts are positive for the myeloid-associated markers CD13 and/or CD33 and negative for Band T-lineage markers (CD3, CD5, CD10, CD19). In this definition the absence of lymphatic and megakaryoblastic markers may be a stronger argument for the myeloid origin of the blasts than the presence of CD13 or CD33, because these markers also may be expressed on nonmyeloid lineages. Leukemias that fulfill the criteria for AML-M0 may therefore be heterogeneous with respect to their origin. This may be reflected by heterogeneity in clinical presentation and behavior, as well as in hematological parameters. Here we describe these characteristics in 14 patients with an acute leukemia classified as AML-MO.

\section{Patients and methods}

In the period from August 1991 to August 1994, the diagnosis of acute myeloid leukemia was made for 656 patients. Fourteen patients $(2 \%)$ were considered to have AML-M0. A review of all peripheral blood and bone marrow smears was performed by the Dutch Slide Review Committee of Adult Leukemias. Morphological analysis was performed on slides stained with May-GrünwaldGiemsa and for the SBB, nonspecific alpha-naphthyl acetate esterase and periodic acid-Schiff (PAS) reaction. The immunological marker analysis on Ficoll-Hypaque-separated mononuclear cells was performed in different laboratories, all members of the Dutch Study Group on Immunophenotyping of Leukemias and 
Lymphomas (SIHON), which organizes biannual quality-control studies [13]. All laboratories used the immunofluorescence technique. The panel of monoclonal antibodies, as recommended by the SIHON, included for the B-cell lineage: CD10 and CD19; for the T-cell lineage: CD3, CD5 and CD7; for the myelo/monocytic lineage: CD13 and CD33. As markers for the blasts cells TdT, CD34, and HLA-DR were used. A leukemia was considered to be positive for a marker if more than $10 \%$ of the blasts were positive for that marker. Cytogenetic analysis was performed in different hospitals, and records from those patients who entered the HOVON-4 therapeutic trial on AML were reviewed by a second center. Seven of the patients were included in this HOVON-4 trial. They received remission-induction therapy consisting of daunorubicin $45 \mathrm{mg} / \mathrm{m}^{2}$ for 3 days, together with ARA-C $200 \mathrm{mg} /$ $\mathrm{m}^{2}$ for 7 days. For six patients this course was followed by a second course consisting of AMSA $120 \mathrm{mg} / \mathrm{m}^{2}$ for 3 days, together with ARA-C $1 \mathrm{~g} / \mathrm{m}^{2}$ two times a day for 6 days. Only three patients received a third course consisting of mitoxantrone $10 \mathrm{mg}$ / $\mathrm{m}^{2}$ together with etoposide $100 \mathrm{mg} / \mathrm{m}^{2}$ for 5 days. Five patients received remission-induction therapy not according to the $\mathrm{HO}$ VON-4 trial, consisting of daunorubicin plus ARA-C (3 patients), thioguanine plus ARA-C (1 patient), or etoposide, mitoxantrone, and ARA-C (1 patient). Two patients did not receive induction therapy. None of the patients was treated with a scheme used for acute lymphoblastic leukemias.

\section{Results}

\section{Patient characteristics}

Patient characteristics are shown in Table 1. Eight of the 14 patients were male. The median age of the patients was 62 years (range 7-77 years). At presentation, lymphadenopathy was found in four patients and hepatosplenomegaly in four. No gingival hypertrophy was found.

\section{Laboratory characteristics}

Laboratory characteristics are also shown in Table 1 . The leukocyte count at presentation ranged from 0.7 to

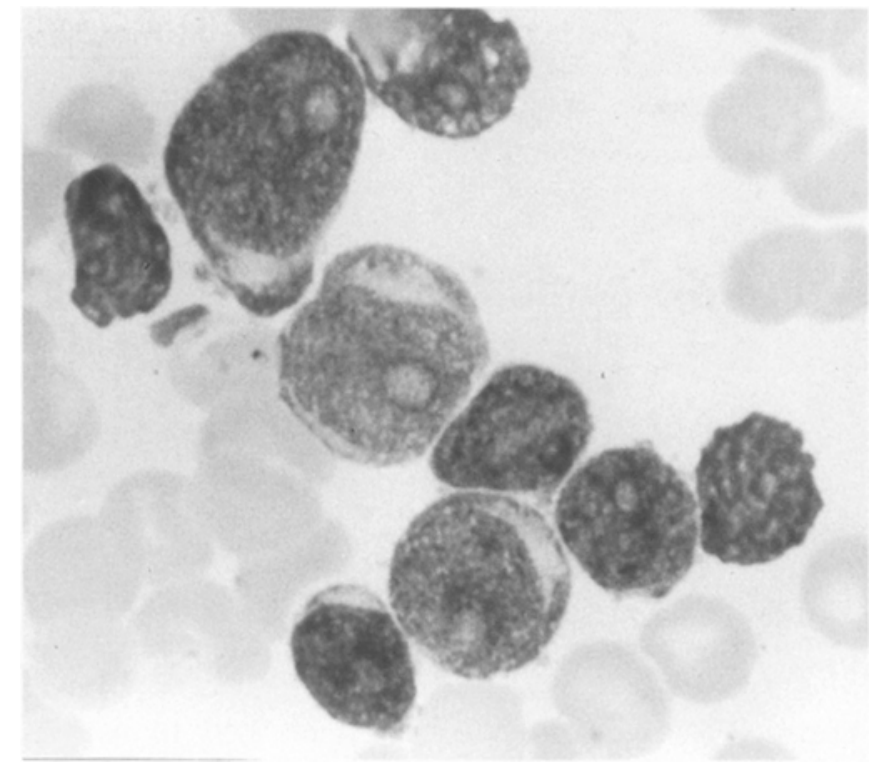

Fig. 1 Morphology of blasts in AML-M0 (May-Grünwald-Giemsa stain)

$214 \times 10^{9} / 1$ (mean $\left.16.7 \times 10^{9} / 1\right)$. Hb ranged from 4.1 to $10.5 \mathrm{mmol} / \mathrm{l}$ (mean $6.3 \mathrm{mmol} / \mathrm{l})$. Platelet count ranged from 8 to $201 \times 10^{9} / 1$ (mean $\left.83 \times 10^{9} / 1\right)$.

\section{Morphology and cytogenetics}

Bone marrow aspirates were hypercellular in all patients and contained a large number of leukemic blasts (mean 79.4\%; range 62.0-92.6\%). Almost no maturing myeloid cells were seen. Peripheral blast count exceeded $50 \%$ in five of the 14 patients (range 1-90). The blasts were small to medium-sized round cells with an eccentric nucleus (Fig. 1). The nucleus often had a flat-

Table 1 Patient characteristics, laboratory characteristics, and treatment outcome in 14 patients with AML-M0 (CR Complete remission)

\begin{tabular}{|c|c|c|c|c|c|c|c|c|c|c|}
\hline $\begin{array}{l}\text { Patient } \\
\text { No. }\end{array}$ & Sex & Age & $\begin{array}{l}\text { Lymph- } \\
\text { adeno- } \\
\text { pathy }\end{array}$ & $\begin{array}{l}\text { Hepato- } \\
\text { megaly }\end{array}$ & $\begin{array}{l}\text { Spleno- } \\
\text { megaly }\end{array}$ & $\begin{array}{l}\mathrm{Hb} \\
(\mathrm{mmol})\end{array}$ & $\begin{array}{l}\text { WBC } \\
\left(\times 10^{9} / 1\right)\end{array}$ & $\begin{array}{l}\text { Plate- } \\
\text { lets } \\
\left( \pm 10^{9} / 1\right)\end{array}$ & $\begin{array}{l}\text { Response to } \\
\text { treatment }\end{array}$ & $\begin{array}{l}\text { Survival } \\
\text { (months) }\end{array}$ \\
\hline 1 & $\mathrm{~F}$ & 7 & - & + & + & 4.7 & 1.46 & 68 & CR after course 1 & Still alive \\
\hline 2 & M & 62 & + & - & - & 6.0 & 78.6 & 41 & No response & 12 \\
\hline 3 & M & 65 & - & - & - & 10.5 & 9.0 & 54 & CR after course 3 & 14 \\
\hline 4 & $\mathrm{~F}$ & 77 & - & - & - & 7.2 & 1.72 & 155 & No response & 4.5 \\
\hline 5 & M & 51 & + & - & - & 6.0 & 1.3 & 24 & CR after course 1 & 20 \\
\hline 6 & M & 60 & + & + & + & 8.5 & 32.1 & 8 & No treatment & 3 \\
\hline 7 & M & 57 & - & - & - & 4.1 & 2.9 & 79 & No response & 3 \\
\hline 8 & $\mathrm{~F}$ & 55 & - & - & - & 5.8 & 2.4 & 112 & $\begin{array}{l}\text { CR after course } 1 \\
\text { No } C R \text { after course } 2\end{array}$ & 4.5 \\
\hline 9 & M & 66 & - & + & - & 5.2 & 8.0 & 12 & Response unknown & 1.5 \\
\hline 10 & $\mathrm{~F}$ & 76 & - & - & + & 6.1 & 2.4 & 54 & No response & 6 \\
\hline 11 & $\mathrm{M}$ & 40 & - & - & - & 6.6 & 0.7 & 201 & No response & 2 \\
\hline 12 & F & 25 & - & - & - & 7.1 & 10.5 & 64 & $\begin{array}{l}\text { CR after course } 1 \\
\text { CR after course } 2\end{array}$ & 32 \\
\hline 13 & M & 70 & - & - & - & 6.9 & 64.5 & 110 & No response & 6 \\
\hline 14 & $\mathrm{~F}$ & 72 & - & + & + & 4.3 & 18.8 & 189 & No treatment & 3 \\
\hline
\end{tabular}


Table 2 Immunological marker expression and cytogenetic analysis of 14 patients with AML-M0 (ND Not done)

\begin{tabular}{|c|c|c|c|c|c|c|c|}
\hline $\begin{array}{l}\text { Patient } \\
\text { No. }\end{array}$ & CD13 & $\mathrm{CD} 33$ & HLA-DR & CD34 & $\mathrm{TdT}$ & $\mathrm{CD} 7$ & Karyotype \\
\hline 1 & - & + & + & + & - & + & Add (12) (p13) \\
\hline 2 & + & + & + & + & - & + & inv (3) (q21 p26) \\
\hline 3 & + & ND & + & + & ND & - & Normal \\
\hline 4 & + & - & + & + & + & - & Normal \\
\hline 5 & + & - & + & + & ND & - & Normal \\
\hline 6 & + & - & + & + & + & - & Normal \\
\hline 7 & + & - & + & + & + & + & $7 q-$, trisomy 13 \\
\hline 8 & + & + & + & + & + & - & Normal \\
\hline 9 & + & + & + & + & + & - & ND \\
\hline 10 & + & - & + & + & + & + & Del 7, trisomy 8 \\
\hline 11 & + & + & + & + & + & + & Trisomy 1 , tetrasomy 4 \\
\hline 12 & + & + & + & + & ND & - & $14 p+$ \\
\hline 13 & + & - & + & + & + & - & ND \\
\hline 14 & + & - & + & + & - & + & $\begin{array}{l}\text { Trisomy } 9 \text {, partial } \\
\text { trisomy } 1\end{array}$ \\
\hline
\end{tabular}

tened shape and was sometimes lobulated or cleaved and contained fine chromatin with several distinct nucleoli. The cytoplasm was lightly basophilic without granules. Vacuoles were seen in three patients and cytoplasmic offspring in four.

SBB staining was negative for eight patients. Alphanaphthyl acetate esterase was positive for five patients and showed in one patient a dotlike pattern. The reaction remained positive after inhibition with natrium fluoride in four patients.

\section{Immunological marker analysis}

The results of immunological marker analysis are shown in Table 2. The blasts of all patients but one were positive for CD13; all showed CD34 and HLADR expression. No leukemias were positive for megakaryoblastic markers. The blasts of three patients were positive for TdT and CD7. They were found to be MPO negative and did not express cytoplasmatic CD22. The blasts in two of these three patients were also negative for cytoplasmatic CD3; in one patient cytoplasmatic CD3 was not measured.

Cytogenetic analysis

The data of cytogenetic analysis are summarized as well in Table 2. No consistent chromosomal aberration was found.

\section{Treatment outcome}

Treatment outcome is shown in Table 1. Four patients achieved complete remission after the first course of chemotherapy. One of these patients is still alive and in complete remission after 17 months. The other 13 patients relapsed and died. The median survival time of the 13 patients who died was 4.5 months (range $1.5-32$ months).

\section{Discussion}

Although since 1991 the AML-M0 as a subtype of acute myeloid leukemia has been described in the FAB classification, the biological and clinical features are not yet clearly defined. Here we describe the characteristics in 14 patients with an acute leukemia that fulfill the criteria for AML-M0. The presenting clinical features of the patients were not distinctive compared with the other FAB subtypes, although the AML-M0 seems to be a leukemia of the older male patient, also described by Sempere et al. [10]. As in other FAB subtypes, there is a wide range in the leukocyte and thrombocyte counts at presentation. In morphological appearance, however, a striking homogeneity of the blasts was seen between patients, being small to medium-sized round cells. The blasts are distinguishable from lymphatic blasts by their fine chromatin and the presence of several prominent nucleoli. A second common feature is the high blast count in the bone marrow and the absence of maturation.

Immunological analysis showed that, irrespective of the expression of one or more myeloid markers, the blasts in all patients were CD34 and HLA-DR positive, pointing to an immature differentiation stage [6]. TdT was positive in the blasts of $72 \%$ of the patients, confirming indeed the immature state of the cells. CD7, a marker found on immature blasts and on $\mathrm{T}$ cells, was found in six of the 14 leukemias, a finding comparable with other reports $[10,11,15]$.

Uniformity is not confirmed by cytogenetic analysis, although in three patients an abnormality of chromosome 7 was found, suggesting an earlier myelodysplastic syndrome. This indicates that the cytogenetic aberrations found are not pathognomonic for the loss of the capacity of the blasts to differentiate. 
Reaction to therapy is poor, with respect to complete remission rate and to survival time, compared with the other AML subtypes [12]. The majority of the patients in our study failed to reach complete remission. All patients died except one, a child, now alive 17 months after diagnosis. Other studies of AML-M0 have shown the same pattern [9-11, 15], complete remission being achieved by two of eight patients [10] and six of 15 patients [11]. All patients but one died within 28 months after diagnosis, with a median survival of 2 months, in the study of Sempere et al. [10]. Stasi et al. found a median survival of 16 weeks [11]. In a third study, comprising five patients, one patient was still alive 16 months after diagnosis, the median survival of the other patients being 2 months [15].

Several factors may account for the poor outcome in this subtype. First, the CD34-positive cells may represent in their population cells with stem cell characteristics. It is known that normal stem cells are in a quiescent state, which make them relatively more insensitive to chemotherapy [14]. Second, a positive correlation between CD34 positivity and the presence of p-170, a glycoprotein that mediates multidrug resistance, is observed [5]. An increased expression of p-170 glycoprotein is also seen in the blasts of refractory patients in other subtypes of AML [7].

In conclusion, our study shows that the leukemias classified as AML-M0 are homogeneous with respect to morphology, showing immature cells without signs of maturation, and with respect to immunophenotype, with positivity for CD34 and HLADR. They have no consistent chromosomal aberration and have a poor clinical outcome compared with AML as a whole.

If AML-M0 is to be considered as an entity, other immature subtypes in SBB-negative acute leukemias may be distinguished based on different marker expression, e.g., lack of both lymphatic and myeloid markers. So far, it is not known whether the immature nonlymphatic subtypes, which may be similar in morphological appearance and are likely to be positive for CD34 and HLA-DR, differ in clinical presentation and outcome from AML M0.

The following persons participated in the Dutch Slide Review Committee of Adult Leukemias: J. van der Lelie, Academical Medical Center, Amsterdam; M. M. A. C. Langenhuijsen, Free Academical University Hospital, Amsterdam; S. M. G. J. Daenen, University Hospital, Groningen; J. C. Kluin-Nelemans, University Hospital Leiden; G. J. den Ottolander, University Hospital Leiden; G. E. G. Verhoef, Gasthuisberg, Leuven, Belgium; M. A. ten Haaft, University Hospital, Maastricht; R. S. G. Holdrinet, University Hospital Nijmegen; H. Mallios, University Hospital Rotterdam; G. E. de Greef, Dr. Daniel den Hoed Cancer Center, Rotterdam; M. B. van 't Veer, Dr. Daniel den Hoed Cancer Center, Rotterdam; H. M. Lokhorst, University Hospital, Utrecht, The Netherlands.

\section{References}

1. Bain BJ (1990) Acute leukaemia. In: Bain BJ (eds) Leukaemia diagnosis, a guide to the FAB classification. Gower Medical, London, pp 1-43

2. Bennett JM, Catovsky D, Daniel MT, Flandrin G, Galton DAG, Gralnick HR, Sultan C (1985) Proposed revised criteria for the classification of acute myeloid leukemia. Ann Intern Med 103:620-625

3. Bennett JM, Catovsky D, Daniel MT, Flandrin G, Galton DAG, Gralnick HR, Sultan C (1985) Criteria for the diagnosis of acute leukaemia of megakaryocyte lineage (M7). Ann Intern Med 103:460-462

4. Bennett JM, Catovsky D, Daniel MT, Flandrin G, Galton DAG, Gralnick HR, Sultan C (1991) Proposal for the recognition of minimally differentiated acute myeloid leukaemia (AML-M0). Br J Haematol 78:325-329

5. Boekhorst PAW te, Leeuw K de, Schoester M, Wittebol S, Nooter K, Hagemeijer A, Löwenberg B, Sonneveld P (1993) Predominance of functional multidrug resistance (MDR-1) phenotype in CD34+ acute myeloid leukemia cells. Blood $82: 3157-3162$

6. Campos L, Guyotat D, Arachimbaud E, Devaux Y, Treille D, Larosc A, Maupas J, Gentilhomme O, Ehrsam A, Fiere D (1989) Surface marker expression in adult acute myeloid leukaemia: correlations with initial characteristics, morphology and response to therapy. $\mathrm{Br} \mathbf{J}$ Haematol 72:161-166

7. Campos L, Guyotat D, Archimbaud E, Calmard-Oriol P, Tsuruo T, Troncy J, Treille D, Fiere D (1992) Clinical significance of multidrug resistence p-glycoprotein expression on acute nonlymphoblastic leukemia cells at diagnosis. Blood 79:473-476

8. Catovsky D, Matutes E, Buccheri V, Shetty V, Hanslip J, Yoshida N, Morilla R (1991) A classification of acute leukemia for the 1990s. Ann Hematol 62:16-21

9. Lee EJ, Pollak A, Leavitt RD, Testa JR, Schiffer CA (1987) Minimally differentiated acute lymphocytic leukaemia: a distinct entity. Blood 70:1400-1406

10. Sempere A, Jarque 1, Guinot M, Palau J, García R, Sanz GF, Gomis F, Pérez-Sirvent ML, Senent L, Sanz MA (1993) Acute myeloblastic leukemia with minimal myeloid differentiation (FAB AML-M0): a study of eleven cases. Leukemia Lymphoma 12:103-108

11. Stasi R, Del Poeta G, Venditti A, Masi M, Stipa E, Dentamaro T, Cox C, Dallapiccola B, Papa G (1994) Analysis of treatment failure in patients with minimally differentiated acute myeloid leukemia (AML-M0). Blood 83:1619-1625

12. Stone RM, Mayer RJ (1993) Treatment of the newly diagnosed adult with de novo acute myeloid leukemia. In: Bloomfield CD, Herzig GP (eds) Hematology/oncology clinics of North America, management of acute leukemia. WB Saunders, Philadelphia, pp 47-64

13. Veer MB van 't, Kluin-Nelemans JC, Schoot CE van der, Putten WLJ van, Adriaansen HJ, Wering ER van (1992) Quality assessment of immunological marker analysis and the immunological diagnosis in leukaemia and lymphoma: a multi-centre study. Br J Haematol 80:458-465

14. Visser JWM, Bekkum DW van (1990) Purification of pluripotent hematopoietic stem cells: past and present. Exp Hematol $18: 248-256$

15. Yokose N, Ogata K, Ito T, Miyake K, An E, Inokuchi K, Yamada T, Gomi S, Tanabe Y, Ohki I, Kuwabara T, Hasegawa S, Shinohara T, Dan K, Nomura T (1993) Chemotherapy for minimally differentiated acute myeloid leukemia (AML-M0). Ann Hematol 66:67-70 